\title{
Development of High Efficiency Swing Compressor for R32 Refrigerant
}

\author{
Yuuichi Yamamoto ${ }^{1}$, Takehiro Kanayama ${ }^{1}$, Kenichi Yuasa ${ }^{1}$ and Hideki Matsuura ${ }^{2}$ \\ 1. Compressor Development and Engineering Group, Daikin Industries, Ltd., Shiga 525-8526, Japan \\ 2. Compressor Development and Engineering Group, Daikin Industries, Ltd., Osaka 592-8331, Japan
}

Received: October 06, 2014 / Accepted: December 01, 2014 / Published: February 28, 2015.

\begin{abstract}
In the age of global warming, energy saving features and overall reduction of environmental impact are critical components that must be addressed when developing new HVAC (heating ventilation and air conditioning) units. We chose R32 refrigerant, with its lower LCCP (life cycle climate performance) as a more sustainable choice than R410A. However, R32 has its drawbacks. Due to its smaller molecular weight, internal leakage loss is higher for R32. Moreover, high discharge gas temperature decreases the reliability of the compressor, and makes a large overheating loss increase. In this study, we will describe the technologies (reducing the piston pressurizing force, heat-insulating structure, optimizing the port diameter) that were developed to overcome these drawbacks. We will also present the performance and reliability of the newly developed high efficiency swing compressor series for R32 refrigerant.
\end{abstract}

Key words: GWP(global warming potential), R32 refrigerant, rotary compressor, swing type, compressor discharge gas temperature.

\section{Introduction}

There is an urgent need to protect the ozone layer from degradation. Regarding to this issue, the Kyoto Protocol was adopted in December 1997, drawing greater attention to the mitigation of global warming. For air conditioning systems, demands for energy saving and reduction of environmental impact are increasing.

As a refrigerant alternative to conventional R410A, we chose R32. Table 1 shows the refrigerant properties of R32.

The GWP (global warming potential) of R32 is about $1 / 3$ of R410A. Since R32 has a high theoretical COP (coefficient of performance), low density, and high refrigerating capacity per unit circulation, this refrigerant produces minimal pressure loss and contributes to the improvement of system performance.

However, R32 has a number of drawbacks. Its molecular weight is small, and this increases internal

Corresponding author: Yuuichi Yamamoto, master, research fields: compressor development. E-mail: yuuichi1.yamamoto@daikin.co.jp.
Table 1 Comparison of refrigerant properties [1].

\begin{tabular}{lll}
\hline & $\mathrm{R} 410 \mathrm{~A}$ & $\mathrm{R} 32$ \\
\hline $\begin{array}{l}\text { GWP*1 } \\
\text { Theoretical COP } \\
\text { (ratio to that of R410A) }\end{array}$ & 2,088 & 675 \\
$\begin{array}{l}\text { Density*2 } \\
\text { (ratio to that of R410A) }\end{array}$ & $100 \%$ & $102 \%$ \\
$\begin{array}{l}\text { Molecular weight } \\
\text { Discharge temperature*2 }\end{array}$ & 73 & $72 \%$ \\
\hline
\end{tabular}

*1: IPCC4 (intergovernmental panel on climate change);

*2: Estimated compressor discharge temperature based on testing conditions $\left(T c / T e / T_{S} / T l=54.4 / 7.2 / 18.3 / 46.1{ }^{\circ} \mathrm{C}\right)[2]$ :

$T c$ : condensing temperature;

Te: evaporating temperature;

$T s$ : suction temperature;

$T l$ : liquid temperature before expansion valve.

gas leakage, which leads to a reduction in compressor performance. Furthermore, reliability of sliding parts in the compressor can be affected because of high compressor discharge gas temperature.

This paper introduces the technologies we developed for solving these problems as well as the newly developed R32-compatible high efficiency swing compressor series incorporating these technologies. 


\section{Compressor Specifications}

\subsection{Swing Compressor Mechanism}

Fig. 1 shows the mechanisms for the swing compressor and the rotary compressor [3, 4].

In a swing compressor, the blade and roller, components for a rotary compressor, are integrated to achieve reciprocated motion of the piston using swing bushes.

Fig. 2 indicates the relationship between the compressor rotational speed and volumetric efficiency of the swing compressor and the rotary compressor [5-7].

Since there is no gas leakage at the section between the blade tip and the roller in the swing compressor, it offers high volumetric efficiency over the entire operating range as compared to the rotary compressor. This tendency can also be observed with R32, which has a smaller molecular weight and is prone to leakage. For this reason, we adopted the swing compressor mechanism.

\section{Issues and Countermeasures}

\subsection{Efficiency}

Fig. 3 shows the comparisons between estimated and actual efficiency of the R410A compressor when operating with R32. The compressor used for this measurement contains refrigeration oil newly developed for R32 [8].

Compressor performance measurements were done

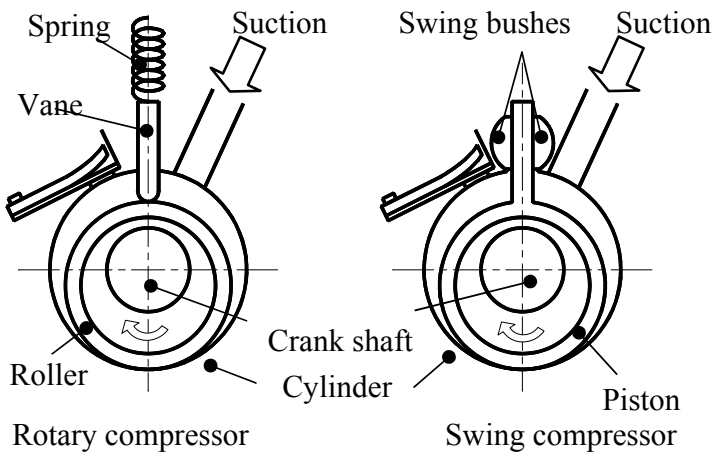

Fig. 1 Mechanisms for swing compressor and rotary compressor.

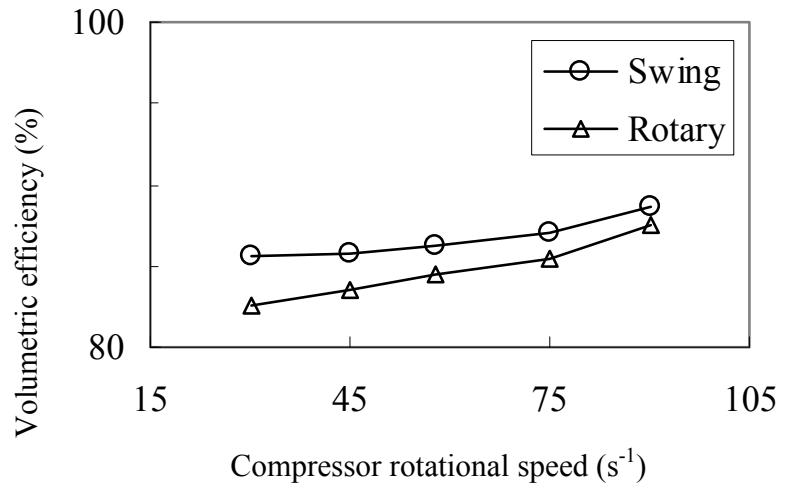

Fig. 2 Comparison of volumetric efficiency in swing and rotary compressors.

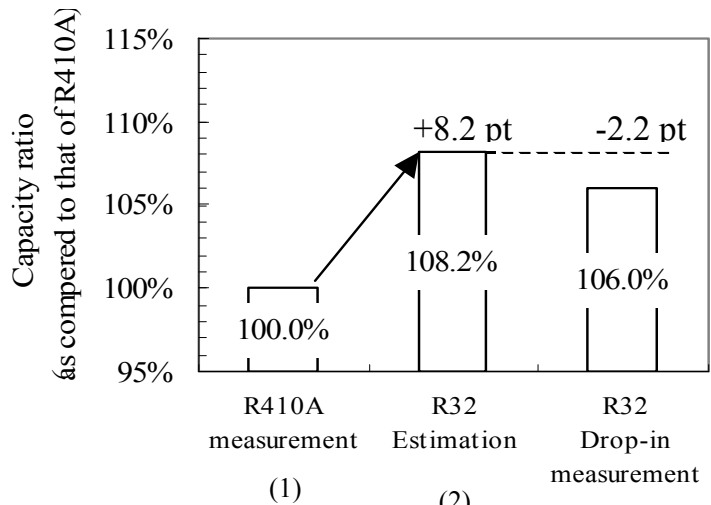

(2)

(3)

Fig. 3 Performance from refrigerant change.

followed by JIS B 8606 (testing of refrigerant compressors).

Fig. 3 (1) is R410A actual measurement used a R410A compressor. Fig. 3 (3) is R32 actual measurement, this test is used the same compressor and the same conditions, difference is used R32 refrigerant and new R32 oil for R410A test. Fig. 3 (2) shows R32 estimation based on R410A test result and changed properties for R410A to R32.

We anticipated an improvement of 8.2 Points because of the differences in refrigerant properties, but the actual improvement was not as much as we expected (6 Points).

The reasons about 2.2-Point difference are because of a large amount of leakage due to the smaller molecular weight and also because of an increase in suction overheating loss due to high discharge gas temperature. 
We did not take a leak and heating into consideration in calculation. Since influence was unknown about a leak and heating. We understood the influence of a leak and heating as 2.2 Points by actual measurements.

To suppress the increase in a suction overheating loss, we created spaces in the parts above and below the compression chamber, as shown in Fig. 4. Since discharge gas does not flow in those spaces, the transfer of heat can be minimized. This improved the efficiency by 0.7 Points, as shown in Fig. 5 .

Furthermore, we optimized the discharge port diameter to take advantage of the reduction in compression loss. Figs. 6-8 show the results of a study on the effects of the port diameter on the volumetric efficiency and indicated efficiency. The smaller discharge port diameter reduces the dead volume, decreasing the amount of re-expansion gas and improves the volumetric efficiency. However, the smaller discharge port diameter results in a narrower discharge passage and increases the flow resistance of the passage during the discharge process, therefore causing an increase in pressure loss.

In the case of R32, we estimated that reducing the diameter by $10 \%$ improves efficiency by 0.7 Points.

Fig. 9 shows the result of the evaluation of an actual compressor incorporating the abovementioned modifications.

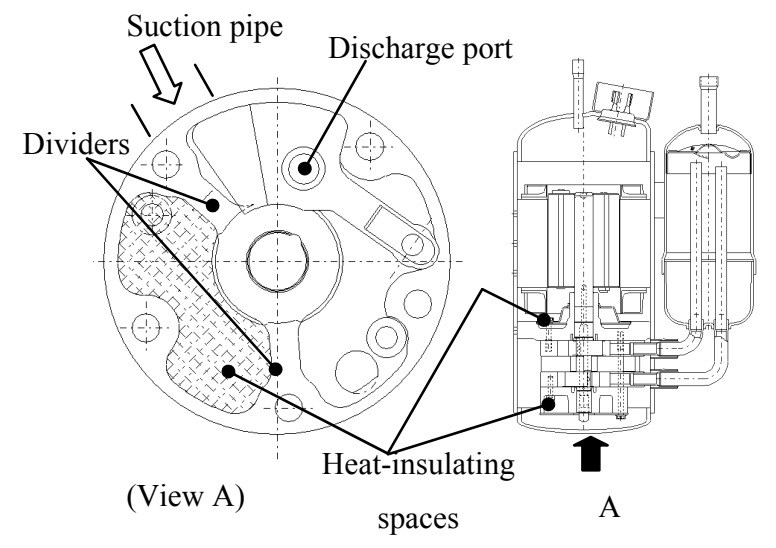

Fig. 4 Layout for heat-insulating space.

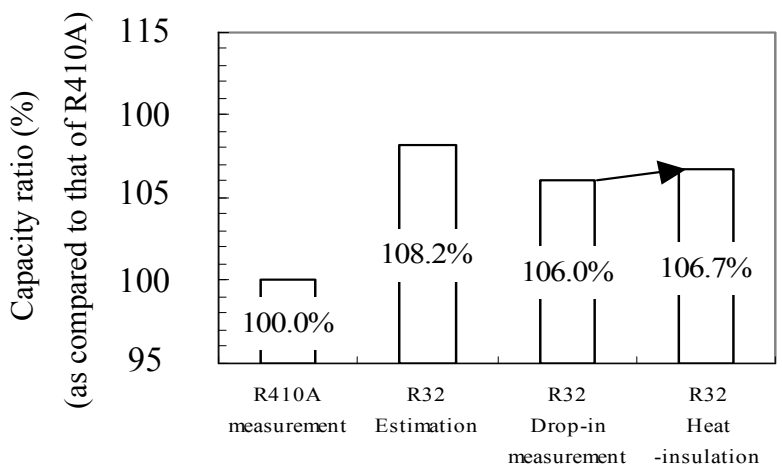

Fig. 5 Heat-insulating effect.

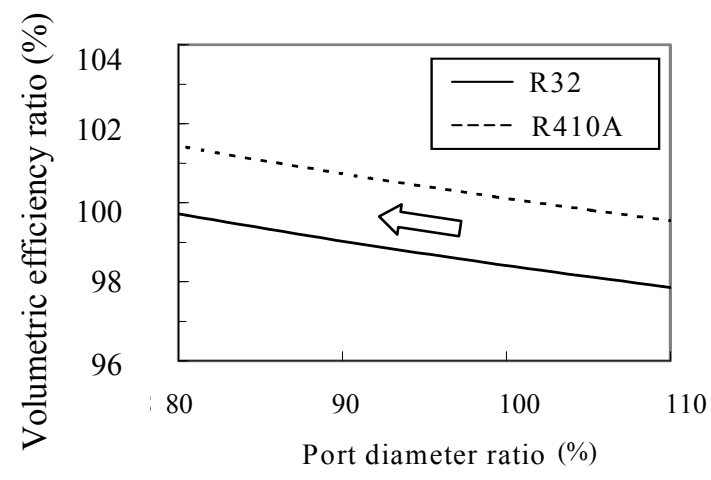

("100\%" given by R410A specification)

Fig. 6 Study of port diameter optimization about volumetric efficiency.

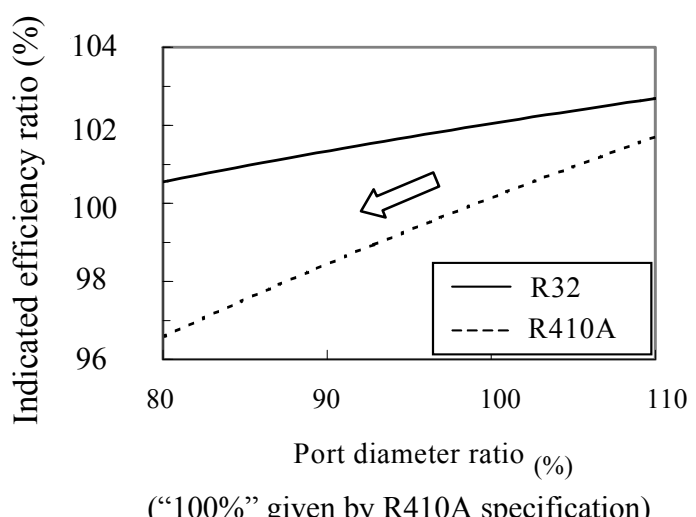

Fig. 7 Study of port diameter optimization about indicated efficiency.

\subsection{Reliability}

We operated an R410A-compatible swing compressor with R32 and newly developed oil for R32 under a high load condition, in which discharge gas temperature is high, and examined the sliding parts. 


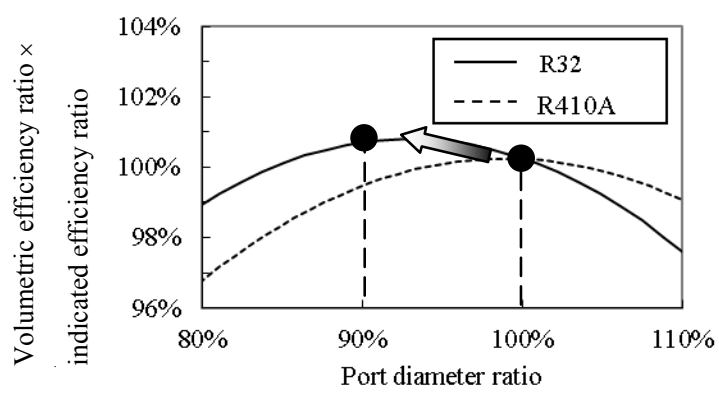

(“100\%” given by R410A specification)

Fig. 8 Study of port diameter optimization about volumetric \& indicated efficiency.

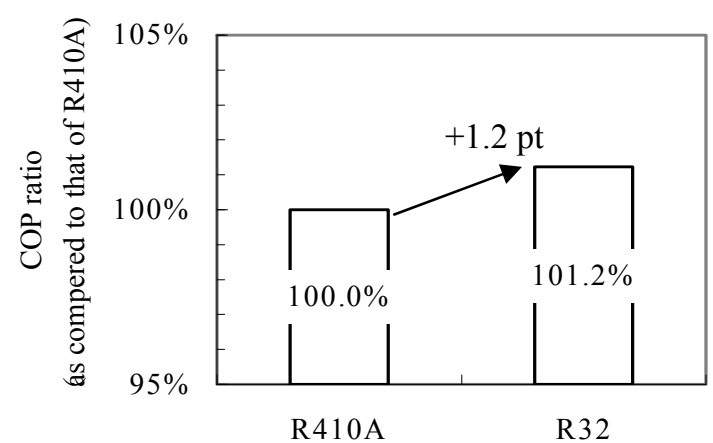

Fig. 9 Effect of sheath.

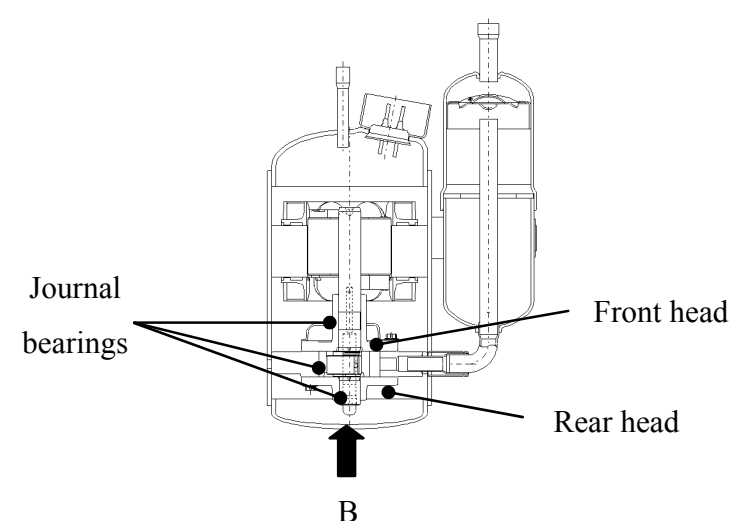

Fig. 10 Section drawing.

Table 2 Result of reliability test.

\begin{tabular}{llll}
\hline Parts & R410A & Result & \\
\hline Journal bearings & $\begin{array}{l}\text { Fluid } \\
\text { lubrication } \\
\text { Boundary } \\
\text { lubrication }\end{array}$ & Good & Not good \\
Front head face & $\begin{array}{l}\text { Surface } \\
\text { roughness }\end{array}$ \\
\hline
\end{tabular}

Fig. 10 shows the section drawing of the compressor used for the examination.

Table 2 shows the result of this experiment.

We confirmed that there was no damage on the journal bearing, but observed a rough surface on the front head face at the location indicated in Fig. 11. There was no metal wear, but an increase in surface roughness. On the rear head face, the roughness was not changed.

The seal lengths of the upper and lower sides of the piston are different. This causes a pressure distribution difference. As a result, the piston was pressed upward, as shown in Fig. 12.

Fig. 13 indicates that the temperatures for discharge pipe are the same. The discharge port gas temperature was higher for R32 than R410A. Particularly in the boundary lubrication region where lubrication efficiency decreased, heat generated by sliding motion could not be dissipated sufficiently. We suspect these were the main reasons for causing the rough surface. The countermeasure taken against is shown in Fig. 14. The seals on the upper and lower sides of the piston have the same length in order to maintain the

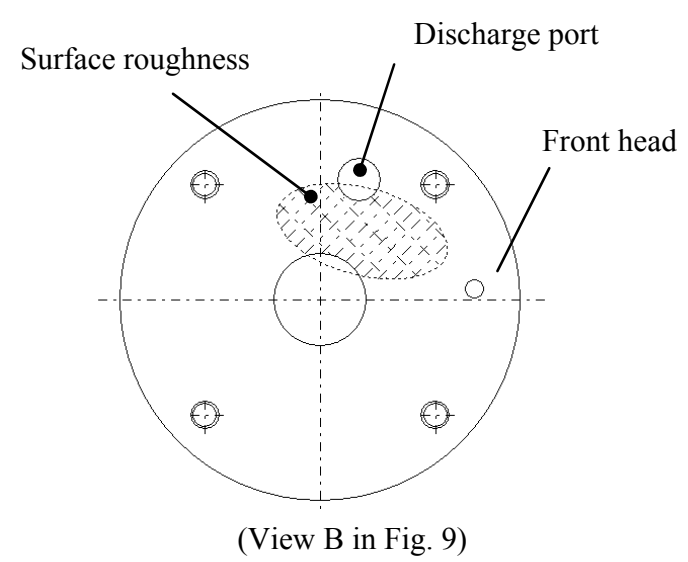

Fig. 11 Damaged section of rough surface.

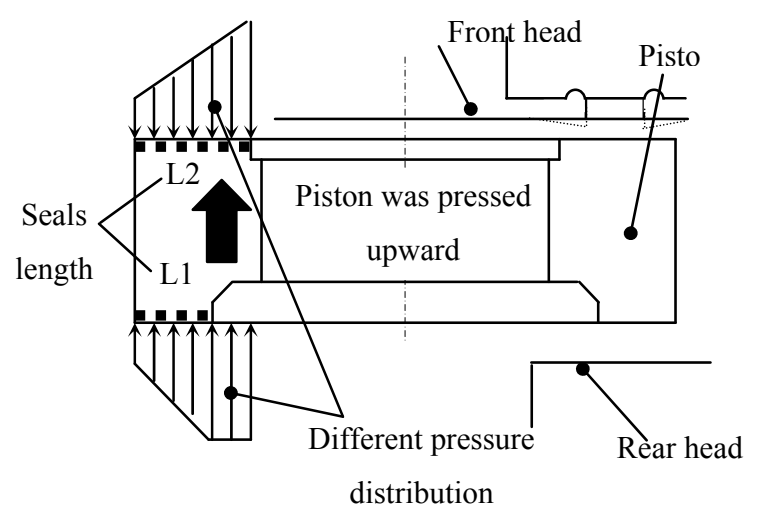

Fig. 12 Shape of original piston. 


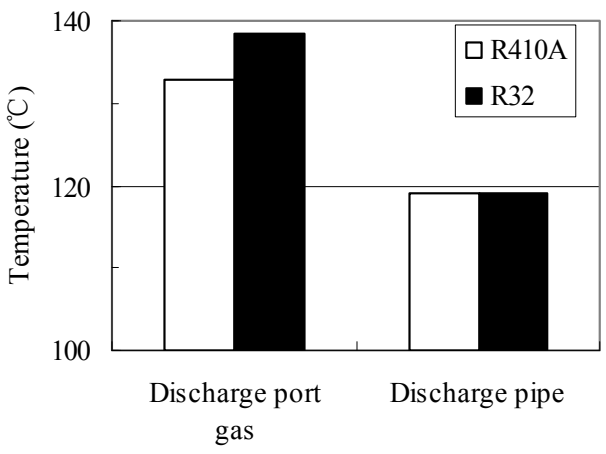

Fig. 13 Internal temperature.

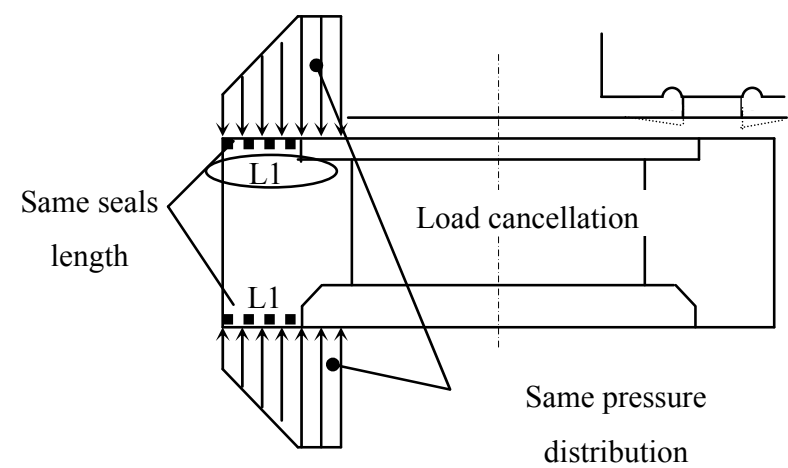

Fig. 14 Shape of countermeasure.

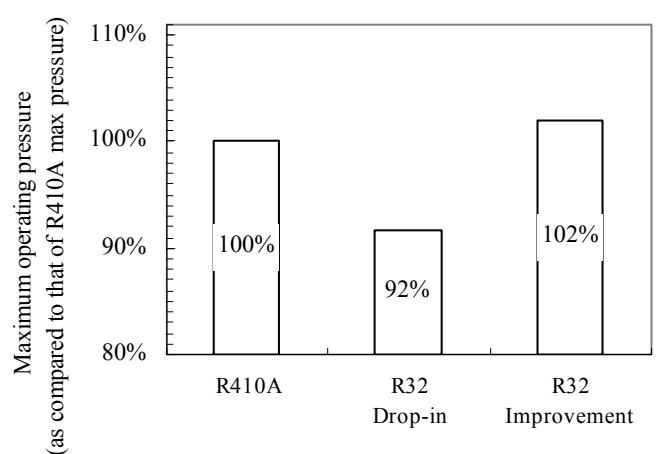

Fig. 15 Confirmation of effect of reliability improvement measure.

even pressure distribution on the upper and lower piston sections. This cancelled the pressing load.

Fig. 15 shows the effect of the countermeasure. This modified piston is ensured to have the same strength compared to the R410A compressor.

\section{Conclusions}

On the basis of our work, we draw the following conclusions:

- We achieved a COP equal to or higher than that of R410A compressor by optimizing the port diameter and adding a heat-insulating structure;

- By reducing the piston pressurizing force, we achieved about the same reliability in the newly developed compressor compared to that of R410A compressor;

- We applied three modifications (optimizing the port diameter, adding a heat-insulation, and seal length of the piston) to conventional R410A compressors and developed R32 compressors with a range of $2.2-10 \mathrm{~kW}$ at (estimating conditions $T c / T e / T s / T l=54.4 / 7.2 / 18.3 / 46.1{ }^{\circ} \mathrm{C}$ )

\section{References}

[1] Taira, S., Nakai, A., and Yajima, R. 2010. "Evaluation and Practical Use of Equipment Using New Refrigerant as an Urgent Countermeasure against Global Warming." In the International Symposium on New Refrigerants and Environmental Technology 2010, 228-31.

[2] AHRI (Conditioning Heating and Refrigeration Institute) 2004. Performance Rating of Positive Displacement Refrigerant Compressors and Compressor Units. ANSI/AHRI Standard 540-2004.

[3] Okoma, K., Tahata, M., and Tsuchiyama, H. 1990. "Study of Twin Rotary Compressor for Air-Conditioner with Inverter System." Presented at the International Compressor Engineering Conference, West Lafayette.

[4] Kato, H., Hasegawa, M., and Morishima, A. 2002. "Development of 2-Cylinder Rotary Compressor Series for Light Commercial Use With R410A." Presented at the International Compressor Engineering Conference, West Lafayette.

[5] Masuda, M., Sakitani, K., Yamamoto, Y., Uematsu, T., and Mutoh, A. 1996. "Development of Swing Compressor for Alternative Refrigerants." Presented at the International Compressor Engineering Conference, West Lafayette.

[6] Furusho, K., Okawa, T., Saitoh, K., and Sakitani, K. 1998. "Numerical and Experimental Investigations of Swing Compressor Characteristics." Presented at the International Compressor Engineering Conference, West Lafayette.

[7] Cliu, J., Yang, and Z., Su. 2001. "Numerical Analysis of Mechanical Losses of Swing Compressor." In Proceedings of the 2001 International Conference on Compressors and Their Systems at London UK.

[8] Tanaka, M., Matsuura, H., Taira, S., and Nakai, A. 2014. "Selection of a Refrigeration Oil for R32 Refrigerant and Evaluation of the Compressor Reliability." Presented at the International Compressor Engineering Conference, West Lafayette. 